\title{
AS ORGANIZAÇÕES INTERNACIONAIS NA HISTÓRIA DAS RELAÇÕES INTERNACIONAIS: ENTRE A GOVERNANÇA GLOBAL E AS ESTRATÉGIAS DOS ESTADOS NACIONAIS
}

\author{
INTERNATIONAL ORGANISATIONS IN THE \\ INTERNATIONAL RELATIONS HISTORY: BETWEEN \\ GLOBAL GOVERNANCE AND THE NATIONAL STATES \\ STRATEGIES
}

Rogério Santos da Costa*

\begin{abstract}
Resumo: Neste artigo procuramos discutir a dinâmica das Organizações Internacionais (OIs) na história das relações internacionais, abordando suas limitações e possibilidades em contribuir como mecanismo de ação coletiva dos Estados nacionais, buscando uma aproximação com os debates acerca da relação das OIs ora com uma "Governança Global", ora com a estratégia dos Estados nacionais. O estudo considera relevante como influência da dinâmica das OIs as premissas do institucionalismo histórico de path dependency, retornos crescentes e conjunturas críticas, além dos ciclos, tanto de Kondratieff da economia-mundo capitalista, como de hegemonia no sistema internacional. O trabalho contém três seções, além das considerações iniciais e finais, abarcando o período pré e pós-criação da Liga das Nações, um outro durante a Guerra Fria, e, por fim, a última parte dedicada ao momento pós-Guerra Fria até a primeira década do novo milênio. Se, por um lado, é possível assumir a dificuldade de as OIs efetivarem seus objetivos diante das estratégias dos Estados nacionais, por outro, é inegável a sua contribuição em algumas áreas específicas do sistema internacional, que podem indicar o embrião de possibilidades para certa "Governança Global".

* Doutor em Ciência Política, Professor do Programa de Pós-Graduação em Administração e dos Cursos de Graduação em Economia e em Relações Internacionais da Unisul, Florianópolis, Santa Catarina, Brasil. E-mail: paralelos@uol.com.br
\end{abstract}


Palavras-chave: Organizações Internacionais; história das relações internacionais; estratégia dos Estados nacionais; governança global.

Abstract: In this article we look forward to discussing the dynamics of international organizations (IOs) in the history of international relations, approaching its limitations and possibilities to contribute to collective action mechanism of national states, seeking to strengthen the debates about the relationship of IOs both with a "Governance Global" and the strategy of national States. The study considers relevant as influence the dynamics of IOs the premises of historical institutionalism of path dependency, increasing returns and critical junctures, beyond the cycles, both Kondratieff in the capitalist world-economy and hegemony in the international system. The work contains three sections besides the initial and final considerations, covering the pre and post creation of the League of Nations, another during the Cold War, and finally, the last part dedicated to the post-Cold War time until the first decade of the new millennium. If, on the one hand, you can take the difficulty of IOs actualize their goals on the strategies of national States, on the other hand, it is undeniable its contribution in specific areas of the international system, and that may indicate an embryo of possibilities to certain "Global Governance".

Keywords: International Organizations; history of international relations; national States strategy; global governance. 


\section{CONSIDERAÇÕES INICIAIS}

As Organizações Internacionais (OIs) fazem parte do conjunto de atores no Sistema Internacional e estão, direta ou indiretamente, envolvidas com os grandes ciclos no desenvolvimento histórico das relações internacionais. Uma peculiaridade põe em dúvida o impacto de sua existência e atuação na ordem internacional, e esta diz respeito a seu aparecimento ser derivado de ações do principal ator nas relações internacionais, os Estados nacionais.

Criadas por Estados, que procuram no meio internacional potencializar seus objetivos nacionais, as OIs servem tanto como mecanismo de ação coletiva, quanto instrumentos para interesses estratégicos específicos de algum ator político-social. Nesta trajetória, historicamente suscitam questões relevantes para o entendimento de seu papel nas relações internacionais, tais como: até que ponto e relevância as OIs moldam o comportamento dos Estados? Se historicamente os Estados deslegitimam as OIs, por que continuam a fazer parte delas? Qual relação pode-se estabelecer entre os ciclos capitalista e de hegemonia com as OIs? É possível apontar um caminho para mudanças no papel das OIs nas relações internacionais a partir da ideia de Governança Global? Ou a natureza do sistema internacional torna perene o limite de atuação desses atores perante os Estados nacionais?

Este artigo pretende auxiliar nas discussões dessas questões com base em uma interpretação do surgimento e desenvolvimento das Organizações Internacionais em seu relacionamento com os grandes períodos da história das relações internacionais. Obviamente, neste sentido, não pretende dar respostas prontas para estas e outras questões que permeiam as OIs, mas sim elencar alguns pontos de vista para o debate profícuo na área de estudos internacionais.

Além dessas considerações iniciais e das considerações finais, o artigo possui ainda 3 (três) outras seções que representam significativos espaços temporais para a história das relações internacionais associadas às OIs. Uma próxima seção é dedicada à Liga das Nações, incluindo o século XIX, que deu origem às primeiras OIs e a outros importantes movimentos que influenciaram o seu aparecimento, atuação e crise. Em seguida faremos uma abordagem no período da Guerra Fria, o que inclui o aparecimento da ONU e a multiplicação do fenômeno das OIs em todo o mundo. Por fim, a última parte engloba o período pós-Guerra Fria até os dias atuais, o que inclui importantes modificações no ambiente internacional com implicações marcantes para a efetividade e a legitimidade das OIs.

Algumas delimitações são necessárias como prévia do desenvolvimento posterior deste trabalho. Consideramos Organização Internacional aquela criada por dois ou mais Estados, através de instrumentos diplomáticos, geralmente um Tratado internacional, e que possui personalidade jurídica própria, Sede, funcionários e orçamento próprio oriundo dos Estados-membros 
e de outras fontes. Isso não significa que outras Organizações de caráter internacional, como as Não Governamentais, Empresas Transnacionais, etc., não tenham relevância no Sistema Internacional, mas sim que não importam para as delimitações deste artigo. ${ }^{1}$

Uma outra dimensão aqui utilizada é a ideia de "Governança Global". Nos últimos dois séculos deu-se efetivamente o início e o amadurecer do fenômeno das OIs, e associada estava e está a ideia de que alguma institucionalização poderia ou pode influenciar a conduta dos Estados e, portanto, a ordem no sistema internacional. Nesse período temos diversas formas sob as quais uma ideia de Governança Global aparecia, e nossa intenção aqui é indicar historicamente essa perspectiva. Apesar de não a utilizarmos diretamente, pensamos que o conceito de Andrew Hurrel assume, principalmente no pós-Guerra Fria, uma boa parte das discussões dessa temática nas Relações Internacionais. Assim, Governança Global seria um ambiente onde prevalecem "Instituições sociais capazes de solucionar conflitos, facilitando a cooperação, aliviando problemas de ação coletiva em um mundo constituído por atores independentes". 2

Outro elemento que consideramos sobre as OIs e sua história nas relações internacionais é que elas são dependentes de trajetória (path dependency). Utilizamos as características adotas pelo institucionalismo histórico para análise das OIs, admitindo que, dada uma formatação assumida pela instituição, tal formatação tende a reproduzir esse padrão, com a sua trajetória histórica inicial sendo retroalimentada por retornos crescentes e a mudança sendo inibida pelos altos custos envolvidos. Conjunturas críticas podem mudar uma trajetória institucional quando são suficientes para impulsionar retornos decrescentes para sua trajetória. ${ }^{3}$

Por fim, consideramos que os fatores que mais influenciam o nascimento e a dinâmica das OIs estão relacionados a temas de economia e/ ou de segurança. O ambiente das Organizações Internacionais é o capitalismo, e neste consideramos relevante a influência dos ciclos de Kondratieff, definidos a partir da ocorrência de períodos de crescimento, estagnação e crise econômica, com importantes influências na política internacional e, consequentemente, nas OIs. ${ }^{4}$

\section{Liga das Nações: influências e consequências de uma curta trajetória}

A Liga das Nações foi o resultado institucional das negociações do pósPrimeira Guerra Mundial, em 191955, fazendo parte do Tratado de Versalhes, que definiu os termos de paz e a tentativa de uma nova arquitetura de poder e ordem no sistema internacional. Ela inaugura uma era de OIs de segunda geração, tendo, portanto, sido influenciada pelas estruturas institucionais inicias no século anterior, relevante na sua formação, no seu histórico e na sua crise. 
O Concerto Europeu surgido do Congresso de Viena em 1815 marcou tanto o fim da disputa sob a hegemonia europeia e mundial, momentaneamente, quanto o início de um período de relativa estabilidade no âmbito mundial, além de ter dado sustentação para que a Inglaterra consolidasse sua posição de motor do capitalismo e grande potência mundial. Nessas condições, o capitalismo se expande, a industrialização se acelera, o comércio entre as nações passa a ser cada vez mais intenso.

Assim, para problemas de ação coletiva entre os Estados e suas economias em constante contato são criadas as primeiras Organizações Internacionais. Estas OIs de primeira geração estão ligadas às necessidades de escoamento de mercadorias entre diferentes territórios e ao uso comum de rios na Europa, como as Uniões Administrativas e as Comissões Fluviais. São consideradas de primeira geração em razão de não possuírem órgão e função política, mas apenas função operacional, sendo exemplo de OIs conhecidas após o advento da ONU como Agências Especializadas. ${ }^{6}$

No mesmo século XIX quando floresceram essas OIs de primeira geração ficaram marcantes as Conferências Internacionais, fenômeno cuja multiplicação depois do Congresso de Viena de 1815 passou a implicar sobremaneira a Liga das Nações. O final do século é marcado por fase descendente dos ciclos de Kondratieff, e o acordo imperialista deságua em grandes diferenças entre as potências e dificuldades na manutenção da paz. Nesse cenário surgem as Conferências de Haia, marcadas para ocorrerem em 1899, 1907 e 1915, tendo esta última não se efetivado em consequência da eclosão do conflito internacional.

Essa fase de institucionalização nas relações internacionais tem uma forte influência do Direito Internacional como tentativa de controlar a ação dos Estados e evitar seus ímpetos belicistas. Conhecida como Legalismo de Haia, o período teve impacto significativo na formação da Liga das Nações e sua arquitetura institucional e legal. Criada sob esse impulso, a Liga esteve desde sua origem associada à noção de um "modelo ideal" e normativo no campo da política internacional, o que associamos à moderna ideia de Governança Global, uma primeira tentativa efetiva, guardadas todas as devidas especificidades de espaço e tempo.

A criação da Liga das Nações contou com alguns elementos influenciadores na sua incapacidade de lidar com os conflitos existentes entre as potências à época, e que, somados ao cenário nas relações internacionais do período entre guerras, delimitou pouca margem de manobra para que a experiência obtivesse grandes êxitos. Dentre estes aspectos relevantes, destacamos: as fragilidades na sua estrutura institucional e legal, a baixa legitimidade, a continuidade do período imperialista e a fase descendente do ciclo de Kondratieff, estes dois elementos que podem ser considerados como um único processo, que se reflete como crise da hegemonia britânica 
no sistema internacional.

Até a Primeira Guerra Mundial já haviam surgido Organizações Internacionais, como as Comissões Fluviais e as Associações Técnicas e Administrativas, mas todas tinham apenas um caráter operacional. A Liga, por sua vez, veio com um propósito de ser a primeira a ter um caráter universal, e instalou também o primeiro grande arranjo institucional de Segurança Coletiva. Esse sistema se refletiu institucionalmente num Conselho composto por nove membros, depois ampliado para quinze, que tinha a incumbência de tratar dos assuntos pertinentes a guerra e paz. Importante notar que as decisões do Conselho eram tomadas por unanimidade, isto é, nas quais todos os 15 membros deveriam votar a favor. Ou seja, na prática todos tinham um direito de veto. Apesar de seu caráter democrático, esse sistema de tomada de decisão foi responsável pela paralisia das decisões da Liga das Nações e, como tratava (ou deveria estar tratando) de questões de guerra e paz, que invariavelmente deveriam ser tomadas de forma rápida, foi também responsável pelos principais problemas da Organização.

Aliadas a essa importante questão estão as genéricas e inaplicáveis sanções que a Carta de criação da Liga produziu. Sem poder contar com o exército supranacional, proposta da França para a Liga, a Organização possuía apenas cláusulas recomendatórias para a utilização de forças por parte dos Estados-membros em caso de ameaça à paz. Quando a Alemanha começou a se rearmar, a Liga não possuía elementos institucionais de imposição da paz que pudessem tentar reverter a situação, o que demonstrava uma imaturidade em termos de OIs.

De fato, não só essa fragilidade institucional explica tal dinâmica, até porque os Estados não possuíam nenhuma experiência anterior à Liga que pudessem utilizar para a diminuição de seus erros. Agregado a isto, a não participação dos EUA como membro da Liga foi fundamental para sua baixa legitimidade, pois, além de ser um país que se fortalecia enquanto potência mundial, com ele também não participaram ou tiveram pouca importância países do continente americano. Assim, a instituição era, de fato, uma organização europeia para dar conta de problemas entre as potências daquele continente e dali para o mundo que dominavam, desde o século anterior.

O Imperialismo, conceituado como fase superior do capitalismo, teve ainda como característica a luta pela partilha do mundo entre as potências europeias em conjunto com os grandes grupos de empresas. A Primeira Guerra Mundial é, na verdade, uma guerra em função dessa dinâmica, uma guerra imperialista, num percurso descendente do ciclo de Kontratieff. A crise de 1929 sacramenta tendência de queda nos lucros e, nesse movimento descendente, torna ainda mais conflituoso o período da Liga. Desta forma, o processo de crise dissertado por $\operatorname{Carr}^{7}$ em seu clássico livro sobre o período aponta a Liga como resultado de visões por demais otimistas em um momento 
de extrema luta, conflito e crise no sistema internacional.

Não fazem sentido, nesta linha, abordagens que indicam fracasso da Liga em relação à ordem no sistema internacional do período. Essa perspectiva aplica-lhe importância demais em um sistema de Estados Nações independentes e autônomos, bem como ignora a crítica e conflituosa situação do período nos aspectos sistêmicos apontados anteriormente.

Assim, a Liga foi uma experiência pioneira e fundamental para o amadurecimento das OIs à época e, principalmente, após a Segunda Guerra Mundial. Importante destacar a criação da Organização Internacional do Trabalho (com o Tratado de Versalhes, em 1919, consolidando movimento do século anterior) e do Comitê Internacional da Cruz Vermelha - CICV (criada em 1863), ainda no século XIX, ambas consideradas sui generis em comparação com as tradicionais OIs intergovernamentais. A OIT tem essa característica em razão de sua composição tripartite (governos, empresários e trabalhadores) e inaugura historicamente o que ficou conhecido no pósSegunda Guerra como Agências Especializadas da ONU. Já o CICV possui como característica única no mundo o fato de ser regido pelo direito interno suíço, em resultado de sua criação naquele país como Organização Não Governamental, mas que foi recebendo mandatos dos Estados partes como guardiã do Direito Internacional Humanitário, sendo, neste sentido, abrigada no Direito Internacional de forma semelhante às demais OIs. ${ }^{8}$

\section{Organizações Internacionais durante a Guerra Fria: entre a proliferação e o congelamento}

O pós-Segunda Guerra Mundial indica o fortalecimento da hegemonia dos EUA nas relações internacionais, em substituição à hegemonia britânica que marcou o período de mais de um século anterior. É possível verificar que desse momento até os dias atuais as OIs tendem a sofrer forte influência de ações e legitimidade por causa de interesses e posição desta nação no sistema internacional. Mesmo assim, igualmente verificamos movimentos de Estados e outros atores internacionais que buscam impor certa autonomia para as OIs em direção ao que ficou conhecido como "Governança Global". Apesar de clara continuidade de existência até hoje das OIs criadas nas primeiras décadas do pós-Segunda Guerra, é importante dividirmos o período em função da predominância da ordem no sistema internacional, marcadamente pela Guerra Fria e seu período posterior.

As negociações em torno do mundo pós-Segunda Guerra realizadas em Dumbarton Oaks - EUA, na segunda metade de 1944, encaminharam a criação da ONU procurando não repetir os erros da Liga das Nações, mas seguindo a trajetória inicial desta enquanto organização de caráter Universal e com diversidade de órgãos. Assim, as Nações Unidas possuem desde a origem um órgão amplo e democrático, a Assembleia Geral (AG), com 
poderes recomendatórios, um Conselho de Segurança restrito e com poderes especiais aos vencedores da guerra, bem como um Secretariado responsável direto pelo zelo aos objetivos a que se propõe a organização. Compõem ainda a organização, desde 1946 com a OIT, as agências especializadas da ONU, mantendo características das OIs de primeira geração, operacionais, mas com órgãos deliberativos próprios, remetendo-as à categoria de segunda geração.

Os princípios contidos na Carta das Nações Unidas (assinada em São Francisco, Califórnia, EUA, em 26 de junho de 1945 criando a ONU) consolidam um histórico amadurecimento e entendimento acerca das relações internacionais, como a solução pacífica de litígios, o respeito à autodeterminação dos povos e o reconhecimento mútuo das soberanias entre os Estados nacionais. Esta edificação, no caso dos direitos humanos, resulta na Resolução 217 da AG, adotada em 10 de dezembro de 1948, e que institui a conhecida "Declaração Universal dos Direitos Humanos", um marco no regime internacional dessa temática.

A nova ordem liderada pelos EUA teria OIs como forma de compensação e manutenção de certo controle em níveis adequados a essa potência hegemônica, a grande vencedora da guerra. Duas grandes dimensões estariam na agenda, a de segurança, com o Conselho de Segurança e depois a Organização do Tratado do Atlântico Norte - OTAN (criada em 1949), bem como a econômica, com o acordo de Bretton Woods e as OIs que estavam atreladas a ele.

O Conselho de Segurança da ONU (CSNU) refletiu em parte a experiência da Liga das Nações, e em parte representa as relações de poder da época de sua configuração. Composto inicialmente por nove membros, teve desde a origem cinco membros permanentes com poderes especiais de veto em diversas instâncias da ONU, não só para Resoluções do CSNU, com destaque para mudanças na própria Carta e na eleição de Secretário Geral.

Esses Estados foram, além dos EUA, a URSS, o Reino Unido, a China (Taiwan até 1971) e compondo por último a França, numa cadeira permanente que só não foi do Brasil em razão do veto soviético e britânico por causa do histórico de atrelamento automático do país aos estadunidenses. Os demais membros são temporários com rotatividade a cada dois anos, sendo que na primeira mudança da Carta da ONU, em 1965, o número de membros temporários passou de 6 (seis) para 10 (dez), ficando o órgão com os atuais 15 (quinze) membros.

Do ponto de vista da experiência da Liga, a restrição do CSNU a cinco membros permanentes tem muito sentido, haja vista que foi esse um dos principais elementos para a paralisia da organização criada no pós-Primeira Guerra. Um órgão que precisa tomar decisões de forma emergencial, em algumas situações e com implicações de Segurança Internacional, precisa ter rapidez para alcançar efetividade. Por outro lado, circunscrito a esses cinco 
membros, perde em legitimidade e em democracia, o que é uma das mais importantes críticas ao seu formato e composição desde sua origem. Essa formatação definiu uma trajetória dependente para a ONU e seu Conselho de Segurança, imprimindo perda constante de legitimidade, assunto que retornaremos adiante neste artigo.

Uma outra fundamental construção com base na experiência da Liga foi o Capítulo VII da Carta das Nações Unidas, cujos artigos compõem o centro do Sistema de Segurança Coletiva da ONU e definem as capacidades e processos para a tomada de decisões de prevenção, imposição e manutenção da paz e segurança internacional. No entanto, no período da Guerra Fria e em consequência do instituto do veto, o Conselho de Segurança e o sistema de segurança coletiva da ONU ficaram "congelados", apenas abrindo espaço para aprovação de Resoluções com interferências onde eram insignificantes os interesses das duas grandes potências do período9. Nessas circunstâncias é que apareceram as Operações de Paz da ONU, que não estão previstas no Tratado da organização, mas que passaram a fazer parte da sua atuação por causa da prática.

Cabe destacar o primeiro golpe desferido contra o sistema de segurança coletiva da ONU. Durante a Guerra da Coreia (de 1950 a 1953), os EUA aprovaram uma Resolução na Assembleia Geral que dava poderes a esse mesmo órgão para, como resultado da inação do CSNU perante um conflito internacional, poder deliberar em questões de segurança internacional, prerrogativa que a Carta da ONU outorgou em primazia ao Conselho de Segurança. Na prática a Assembleia Geral se autoconcedeu poderes que só uma Reforma da Carta poderia ter feito. Utilizada como legitimadora da entrada dos EUA na referida guerra, a Resolução "Unidos para a Paz" foi um dos momentos mais negativos que marcaram a organização.

$\mathrm{Na}$ vertente econômica importante arranjo foi estabelecido no pósSegunda Guerra. Trata-se dos Acordos de Bretton Woods (BW), de 1944, que instituíram um sistema relativamente fixo de conversibilidade de moedas internacionais, conhecido como padrão ouro-dólar, bem como criaram o Fundo Monetário Internacional - FMI para gerenciá-lo. Além disto, foi criado também neste momento o Banco Internacional de Reconstrução e Desenvolvimento, inicialmente como principal braço da aplicação do Plano Marshall de reconstrução da Europa. A outra organização criada em BW, a Organização Internacional do Comércio - OIC, acabou não sendo efetivada em virtude do veto do Congresso dos EUA, sendo utilizada em seu lugar o Acordo Geral de Tarifas e Comércio - GATT. Desde então os EUA difundem a ideia do liberalismo econômico como instrumento benéfico a todas as nações, mas obtendo especiais vantagens diante de acordos benéficos as suas competitivas empresas.

O pós-Segunda Guerra Mundial é marcado pelo início de um novo 
movimento expansivo na economia mundo capitalista, configurando um novo ciclo Kondratieff, conhecido como os "Trinta gloriosos" (1945-1975). Na década de sessenta esse ciclo começa a perder força, resultando nas crescentes dificuldades dos EUA de manterem-se no padrão ouro-dólar. Assim, no início da década de setenta o sistema monetário internacional montado em BW é abandonado e passa-se a vivenciar um "não sistema", com flutuação cambial, embrião de um Sistema Financeiro Internacional que cada vez mais ganhou autonomia depois daquele período. O inicio deste processo se deu com uma decisão unilateral dos EUA, sob a presidência de Richard Nixon, em 1971, e que foi seguida pelas principais nações industrializadas em 1973. ${ }^{10}$

A década de sessenta também assiste aos primeiros encontros de Bancos Centrais dos países centrais, embrião do que ficou conhecido como G7, a partir de 1975, apesar de existirem reuniões destes desde meados da década de sessenta em função das dificuldades do sistema de BW. Esse Grupo, que não é uma instituição internacional, tem sido responsável pelas principais articulações financeiras e macroeconômicas dos países capitalistas centrais desde então, aproximando-se de uma "Governança econômica global", mas com claros interesses particulares de seus membros.

Um necessário destaque do período é que, a despeito da existência do FMI para a regulação do padrão monetário, uma vez que este último deixou de ser atrativo e um interesse da principal potência capitalista, os EUA, então ele caminhou para o fracasso e o fim. Neste sentido, a capacidade de uma OI em determinar as ações de um Estado ficam notadamente limitadas ao tamanho e importância deste na arena internacional. Sem funções específicas na área da conversibilidade de moedas para a qual foi criado, o FMI passa a gerenciar as crises dos países em desenvolvimento a partir do choque monetarista da virada da década de setenta para oitenta. Na década de setenta ocorrem os choques do petróleo, em 1973 e 1979, significando aumentos expressivos nos preços do produto com a articulação dos países exportadores membros da Organização dos Países Exportadores de Petróleo - OPEP (criada em 1960).

Apesar de estar também associada a um Cartel, a ação da OPEP põe em xeque a capacidade dos países mais poderosos de imposição de suas vontades aos países mais frágeis, bem como abre expectativas para as possibilidades de OIs no sistema internacional. Dos debates sobre esses acontecimentos e suas repercussões à época, surgem as teses de que estaríamos entrando numa era de Relações Transnacionais, com larga participação de empresas transnacionais, culminando na perspectiva liberal da interdependência complexa ${ }^{11}$. Desta linha de interpretação das relações internacionais se alimenta grande parte das concepções que reforçariam, a partir da década de noventa, a ideia de Governança Global.

O período da Guerra Fria assiste, da mesma forma, a uma modificação fundamental na Assembleia Geral das Nações Unidas e em outras arenas 
institucionais e ad hoc do sistema internacional. Com o processo de independência de vários países colônias, principalmente africanos, a composição na $\mathrm{AG}$ passou a ser mais complexa e de difícil controle por parte dos EUA e aliados, bem como para a URSS, desde a década de sessenta. A partir de então, e cada vez mais, a AG passa a ser um locus de aparecimento de movimentos que discordam da posição das grandes potências, transformandose num ambiente de intenso debate sobre assuntos de grande interesse global e específicos de alguns grupos de países de menor importância. Apesar do caráter apenas recomendatório de suas Resoluções, portanto de sua baixa efetividade, a AG abriga uma intensa experiência de Democracia na arena internacional, de onde temas ganham relevância e se transferem, em alguns casos, em agendas internacionais significativas.

Nesse processo de descolonização se constitui a articulação dos países pobres e em desenvolvimento, tendo como primeiro passo o Movimento dos Não Alinhados - MNA, na Conferência de Bandung, na Indonésia, em 1955, e que na década de sessenta daria luz para a ocorrência, em 1964, da Conferência das Nações Unidas sobre Comércio e Desenvolvimento UNCTAD, que se constituiu como órgão da AG da ONU. Com a UNCTAD e o MNA a ordem instituída no pós-Segunda Guerra Mundial passa a ser questionada, seja no âmbito da bipolaridade EUA-URSS, seja na condução pelos países desenvolvidos das negociações de liberação comercial no âmbito do GATT. O próprio conceito de desenvolvimento passa a ser objeto de debate, tendo observado significativa transformação no período pós-Guerra Fria, como se verá adiante.

É de se salientar, da mesma forma para o período da Guerra Fria, a construção da OTAN, figurando como o braço militar-estratégico dos EUA na disputa com o bloco socialista (que formou o Pacto de Varsóvia - 1955 a 1991 - com o mesmo propósito), e cuja continuidade de existência após a mudança da ordem bipolar é fator fundamental de entendimento sobre a trajetória das OIs. Da mesma forma, cabe realçar a proliferação de OIs em todo o mundo, seja de organizações regionais em todos os continentes, de caráter técnico, administrativo ou político, como a Organização dos Estados Americanos - OEA (1948), a Liga dos Estados Árabes (1945) e a Organização da Unidade Africana - OUA (1963), ou de Agências Especializadas da ONU. As Conferências da ONU para determinado tema que entrava na agenda internacional invariavelmente resultam em regimes internacionais e, com elas, institucionaliza-se a permanência do debate e ação com a criação de uma Organização Internacional. Assim é que chegamos ao fim da Guerra Fria com mais de duas centenas de OIs no mundo.

Muito significativa foi a articulação, já na década de cinquenta, da integração dos países da Europa ocidental com a constituição das Comunidades Europeias. Desde a sua origem possuidoras do instituto da 
supranacionalidade, por isso essas Comunidades podem ser consideradas como OIs de terceira geração, dando impulso ao fenômeno do regionalismo para integração regional em praticamente todo o mundo, a partir da década de sessenta. Apesar de sua especificidade e importância adquirida na arena internacional, a integração europeia ainda é um campo muito fértil de debate acerca das características de sua institucionalização, podendo ser considerada tanto uma OI sui generis como uma Confederação de Estados, algo como os "Estados Unidos da Europa". ${ }^{12}$

\section{As OIs do pós-Guerra Fria aos nossos dias: da euforia à deslegitimação}

$\mathrm{Na}$ década de noventa conhecemos um movimento de muita euforia e desilusão em torno do papel das Organizações Internacionais nas relações internacionais. Não só pela queda do muro de Berlim, em 1989, mas principalmente pelos desdobramentos da Guerra do Golfo, em 1990. Quando em 2 de agosto de 1990 o Iraque invadiu o Kuwait e no mesmo dia o Conselho de Segurança da ONU emitiu a Resolução 660/90, poderia estar ocorrendo o início da atuação efetiva das OIs para influenciarem os Estados-membros. ${ }^{13}$

A euforia se justificava. Considerado "congelado" praticamente desde sua criação, o CSNU estava por implementar medidas até então inéditas em um Estado-membro. Pela primeira vez o Conselho admitiu que um membro cometeu uma agressão a outro e que houve uma clara ruptura da paz e da segurança internacional. Depois de rápidos passos na direção de uma saída negociada do Iraque do Kuwait, em 29 de novembro do mesmo ano o Conselho adotou aquela que seria uma decisão utilizada em outras circunstâncias e que causa muita controvérsia quanto à legitimidade da $\mathrm{ONU}$ na arena internacional.

Trata-se da Resolução 678/90, que deu ampla autorização a todos os demais Estados-membros da ONU para fazerem cumprir a Resolução 660/90, que exigia a saída incondicional do Iraque do território ocupado e anexado e que, literalmente, autorizou os Estados a utilizarem "todos os meios necessários" para fazer valer a decisão do CSNU. A Guerra do Golfo teve seu desfecho com a derrota do Iraque, e o acordo de paz teve guarida na Resolução 687/91, de 3 de abril de 1991. Essa mesma decisão originou um Regime de verificação de armas de destruição em massa, um arranjo ad hoc e centro de vários movimentos em segurança internacional dali em diante, todos envolvendo esses instrumentos decisórios do CSNU. Com o passar dos anos nessa década, os arranjos ad hoc passaram a ser utilizados como forma de retirar temas de segurança do centro decisório institucionalizado, o CSNU.

Aaplicação da Resolução 687/91 e do próprio Regime que se inaugurara passa a ser um elemento de crescente deslegitimação da ONU. Deixada sob a liderança dos EUA, aos poucos a atuação sob o Iraque passou a extrapolar os poderes delimitados pelo Conselho nas Resoluções, apontando para uma 
precoce derrocada da euforia que se estabeleceu no início do processo. É importante notar que os EUA foram redefinindo sua política de defesa nacional desde o imediato pós-Guerra Fria, implementando a estratégia de "Segurança Preventiva", a qual seria reforçada após os acontecimentos de 11 de setembro de 2001. No desenrolar da década de noventa esse movimento significou uma crescente dificuldade para a legitimação da ONU como locus de resolução de conflitos internacionais, dando sinais para a crença num mundo unipolar comandado pela superpotência militar e econômica da América do Norte.

$\mathrm{O}$ movimento de euforia resultou numa significativa convergência com os ideais de Boutros Boutros-Ghali, eleito Secretário Geral da ONU em 1992. A reunião de cúpula do CSNU de janeiro do mesmo ano, inédita na história da organização, e o relatório intitulado "Uma agenda para a paz" davam credenciais a Boutros-Ghali liderar um fortalecimento da ONU em direção ao multilateralismo esperado desde a sua criação. No entanto, o veto dos EUA à tradicional recondução de um Secretário Geral a um segundo mandato, em 1996, aponta para direção contrária.

As dificuldades da ONU em lidar com conflitos no pós-Guerra Fria ficam evidenciadas na incapacidade com a prevenção ao genocídio ocorrido em Ruanda, em 1994, bem como com as complexas relações entre os povos de uma Iugoslávia em desintegração, a partir de 1991. A Guerra de Kosovo e a atuação da OTAN, em 1998, sem um mandato expresso do Conselho de Segurança da ONU, impõem uma ferida muito grave na legitimidade da organização ${ }^{14}$. Apesar da resistência da França em manter a OTAN funcionando após o período bipolar, essa organização militar amplia seu conceito estratégico para se capacitar em uma ampla frente de possibilidades de intervenções, tanto do ponto de vista da justificativa quanto do escopo territorial. A intervenção em Kosovo é a primeira oficial da organização militar do Atlântico Norte fora dos domínios dos Estados-membros, bem como sob o argumento de evitar uma crise humanitária. De assuntos interestatais, a segurança internacional passava a ter cada vez mais um tratamento intraestatal, seja por parte do CSNU, seja da OTAN.

Quando em 1998 a Índia e o Paquistão demonstravam suas capacidades nucleares, também indicavam certa incapacidade da Agência Internacional de Energia Atômica - AIEA (criada em 1957) em manter fechado o Clube de Estados nucleares, bem como de encaminhar o regime para uma convivência mais equilibrada entre o uso pacífico e bélico da tecnologia nuclear. Essa problemática se estenderia para a questão nuclear iraniana na década seguinte, assim como para a total incapacidade e falta de efetividade para tratar com a questão Israel-Palestina.

No âmbito econômico a dinâmica das Organizações Internacionais é muito semelhante à temática de segurança, apesar de ter contornos mais definidos na primeira década do novo milênio. Na esteira da euforia, os Estados 
participantes da Rodada Uruguai do GATT criaram em 1995 a Organização Mundial do Comércio - OMC, no que seria um importante passo na busca da liberalização do comércio internacional. No entanto, a Rodada Doha, que sucedeu a Rodada Uruguai, demonstra as dificuldades de ampliação da liberalização que marcaria a área de comércio na primeira década do novo milênio, principalmente num ambiente em que países em desenvolvimento passam a se articular em busca de reciprocidade maior nas negociações.

A década de noventa também foi palco da aceleração do processo de mundialização, alicerçado pelo fim das amarras políticas da Guerra Fria, mas igualmente auxiliado pela revolução nas telecomunicações desde a década de setenta. A criação de um Sistema Financeiro Internacional se deu sob o signo do liberalismo e da flexibilização, amplamente impulsionados pela capacidade de contato mundial entre bancos e instituições financeiras. $\mathrm{Na}$ segunda metade da década de noventa o SFI sofre sua primeira grande crise, abalando países asiáticos em primeiro lugar, se espalhando em seguida para os principais países em desenvolvimento.

A desregulamentação financeira desde a década de sessenta aplicada primeiramente pelos países centrais estava revelando uma face até então menos impactante na economia mundo, que tomou contornos de agravante na fase de crise do ciclo de Kondratieff. Países da América Latina, em especial, sofreram duras consequências por estarem atrelados e fragilizados nesse processo, pois que apostaram no neoliberalismo pós-Consenso de Washington como forma de melhorarem suas inserções internacionais. Assim como na década de oitenta, quando o FMI passou a ser o gerenciador das crises dos países em desenvolvimento, na década de noventa continuou a aplicar os mesmos "remédios" de política econômica ortodoxa. O fracasso na resolução dos principais problemas macroeconômicos desses países, bem como a incapacidade de evitar a crise financeira internacional de fins daquela década apontam para o Fundo Monetário Internacional como uma instituição em decadência, só resistindo em existência em virtude de ainda servir aos propósitos de seus sócios maiores. Porém, o fenômeno não é exclusividade do FMI, pois a sobrevivência e continuidade de existência de uma OI mesmo depois de sua debilidade e crise por falta de efetividade é um padrão encontrado na história das OIs.

A outra OI oriunda dos Acordos de Bretton Woods não teve trajetória muito distinta. O Banco Mundial (como ficou conhecido o conjunto de instituições financeiras surgidas após a criação do BIRD) passou a década de oitenta financiando Estados com dificuldades no Balanço de Pagamentos, em conjunto com o FMI. Ao entrar a década de noventa já se faziam fortes as discussões em torno do conceito de desenvolvimento, muito em razão dos desenvolvimentos e vitórias conseguidas por meio da UNCTAD. É do confronto de conceitos sobre desenvolvimento que se estabeleceu uma nova 
forma de abordagem dessa temática dentro da ONU, com pressões de destaque sobre o Banco Mundial. As formas de Cooperação para o Desenvolvimento marcadas pelas relações Norte-Sul se inclinam a novos caminhos que fortalecem as relações Sul-Sul. Um dos resultados desse confronto conceitual é o estabelecimento, em 2000, dos Objetivos de Desenvolvimento do Milênio - ODM para serem alcançados até 2015.

O conceito de Governança, difundido pelo Banco Mundial para tratar da boa prática pública e de gestão dos Estados, principalmente os mais frágeis, passa a ter contornos globais ao ser incorporado ao discurso de desenvolvimento em suas diferentes variáveis, notadamente desenvolvimento humano e desenvolvimento sustentável. Ganha corpo a ideia de Governança Global, aplicada a determinados temas de interesse de todos os atores no sistema internacional, graças à suposta interdependência que o processo de globalização explicitou. Um dos principais pilares dessa ideia encontra-se nos debates sobre o Regime do Clima, em face das drásticas mudanças climáticas que o planeta estaria sofrendo. O locus dessa discussão é, sobretudo, nas Conferências do Clima da ONU, o qual passa a ser, desde Estocolmo em 1972, mas principalmente após a Rio 92, um dos principais pilares de atuação da Organização.

O início do novo milênio tem uma trajetória de agravamento das tendências já verificadas na desilusão com relação ao papel das OIs num mundo sem o conflito bipolar. O ponto inicial e fundamental dessa nova etapa são os acontecimentos de 11 de setembro de 2001 nos EUA. Tal momento destravou mecanismos preparados pelos EUA para sua Guerra Preventiva sob a roupagem de Guerra ao Terror. Para os nossos propósitos, significou a contínua e explícita trajetória de deslegitimação do Conselho de Segurança da ONU em questões de Segurança Internacional, que leva à falência o modelo de Segurança Coletiva constituído em 1945, principalmente seu mecanismo de membros permanentes e sua capacidade de veto.

A começar pelo imediato pós-ataques de 11 de setembro, quando, envolvidos por certa comoção mundial, poucos se deram conta de que a investida que os EUA fizeram no Afeganistão governado pelo Grupo Talibã não possuía um mandato expresso do Conselho de Segurança. Foi, portanto, uma agressão a um Estado soberano, apesar de estar com baixo reconhecimento e legitimidade internacional em seu governo. Na sequência tivemos vários outros momentos que demonstram clara falta de interesse em manter legítima uma organização internacional como a ONU. Destaca-se deste primeiro movimento a utilização da OTAN para comandar a ocupação a partir da capital Cabul, numa primeira missão oficial dessa organização fora do espaço do Atlântico Norte.

A invasão ao Iraque, em 2003, foi feita pelos EUA da mesma forma que no Afeganistão, sem um aval da ONU, e sob justificativa da existência 
de armas de destruição em massa. A Comissão de Verificação de Armas no Iraque, criada de forma ad hoc pelo CSNU, não indicava nenhuma definição sobre a existência ou não de tais armas no solo iraquiano, e ainda estava a trabalho naquele país quando da decisão da invasão. A relação da Comissão com o Iraque foi de muita tensão, seja quando o governo iraquiano dificultava o acesso a determinados locais no país, seja quando confirmada a existência de membros da Comissão envolvidos em espionagem para os EUA. Apesar disto, os estadunidenses apontavam o fato de o Iraque de Saddam Hussein ter descumprido a Resolução de cessar fogo de 1991, de número 687/91, a qual, nestes termos, estava sob o mandato da Resolução 678/90, que dava amplos poderes aos Estados-membros, sob a expressão "todos os meios necessários".

Em virtude do regime de não proliferação de armas químicas, em 1997 foi criada a Organização para Proscrição de Armas Químicas - OPAQ, que teve como primeiro Diretor Geral o brasileiro José Maurício Bustani. Em 2002, Bustani foi retirado de seu cargo por uma manobra não prevista no Tratado Constitutivo da Organização, sob argumento de "má administração", ferindo a autonomia e o respeito ao enunciado legal da OI, numa clara demonstração de insatisfação por parte da grande potência.

$\mathrm{Na}$ verdade, o que incomodou os estadunidenses foi o trabalho de Bustani, que feria aqueles interesses em dois caminhos. Um era a vontade de fazer valer inspeções nas instalações de indústrias químicas daquele país, como em qualquer outro país membro; o outro foi ter conseguido trazer o Iraque para a OPAQ, o que retiraria dos EUA a base de justificativa para a invasão que pretendiam. Em 2003 o Tribunal Administrativo da OIT reconheceu nula a decisão de retirada de Bustani, decisão que restaurou um pouco a credibilidade das OIs em sua relação com Estados poderosos, reforçando a necessidade de amparo legal para a sua tomada de decisões.

A invasão ao Iraque deixou uma marca de deslegitimação para o Conselho de Segurança, a quem os EUA ainda tentaram recorrer, antes de efetivamente agirem militarmente. O fato é mais grave para a ONU e as OIs porque efetivamente não foram encontradas armas de destruição em massa, além de ter deixado uma situação de caos naquele país. Fica ainda como grande mancha, para a ONU, a morte de um dos seus mais altos representantes em 2003, Sérgio Vieira de Melo, após um ataque a bomba na sede da missão da organização que estava com a responsabilidade de auxiliar na reconstrução do país.

Na esteira da "Primavera Árabe", iniciada em 2010, ainda haveria mais um momento de complicações para a combalida legitimidade do Conselho de Segurança. A Líbia entrou na onda das manifestações com opositores do Governo de Muammar Gadaffi tentando derruba-lo, criando uma situação de guerra civil com mortes de civis não combatentes. O Conselho de Segurança, após medidas de embargo contra o Governo Líbio, aprovou uma Resolução 
em que assegurava aos Estados-membros “todos os meios necessários" para a proteção dos civis em território sírio, aprovando a participação da OTAN em operações aéreas. Além das incursões em alvos residenciais mirando Gadaffi e sua família, é de se estranhar que, após a captura e morte deste, o Comandante das operações da OTAN tenha simplesmente declarado que estava alcançado o objetivo da missão na Líbia, não havendo mais motivo para sua continuidade. A Resolução 1973/2011 do CSNU tinha como objetivo a defesa dos civis no que se tornara uma guerra civil na Líbia, e não a derrubada do governante daquele país, muito menos sua morte.

Assim, o resultado para o CSNU de quinze anos deste primeiro milênio é uma crescente escalada de deslegitimação. As discussões sobre uma ampla reforma nesse principal órgão da ONU é cada vez mais constante, muito em razão dessa perda de legitimidade, mas não apenas pelas ações neste trabalho apontadas. De fato há uma nova configuração de poder no cenário internacional, e ela difere substancialmente dos contornos quando da criação da organização, no imediato pós-Segunda Guerra. Países grandes potências como Alemanha e Japão, bem como emergentes potências regionais como Brasil e Índia passam a reivindicar espaço de destaque no clube dos membros permanente. No entanto, o formato inicial de veto dos membros permanentes, dando-lhes a prerrogativa de aceitarem ou não uma mudança na composição, revela uma dependência de trajetória que só uma reversão dos retornos que os cinco Estados possuem para ocasionar uma transformação profunda. Isso talvez já esteja se processando.

O novo milênio abriu algumas perspectivas de análise sobre ordem internacional que demonstram uma queda relativa da hegemonia dos EUA, com a ascensão de países até então semiperiféricos, como China, Índia, África do Sul e Brasil. Reforçam-se, em conjunto com a Rússia, as relações Sul-Sul que em certa medida criam obstáculos às ações dos países centrais. A articulação do BRICS, criando instituições como um Banco de Desenvolvimento e um Fundo de ajuda financeira mútua, indica movimentos de dificuldades para a hegemonia estadunidense. Um outro dado importante é a substituição do dólar como fonte principal de comércio exterior, com muitos países e grupos de países passando a utilizar suas próprias moedas nacionais, sem a moeda dos EUA como equivalente de troca.

Um reflexo dessas dificuldades é a dinâmica da Rodada Doha da OMC. Fruto de uma articulação dos países em desenvolvimento liderados pelo Brasil, houve a criação do G20 comercial. O Grupo buscou se fortalecer nas negociações comerciais para alcançar reciprocidade real na relação com os países centrais dentro da organização, o que incluía abertura maior na agricultura de EUA e Europa. Essa paralisia acaba por demonstrar os limites de um mundo liberal completo e fortalece a ideia de que o liberalismo dos países centrais é uma fórmula coerente apenas naqueles setores em que são 
altamente competitivos. Neste caso, e enquanto exemplo, para outros também, não significa uma "falha institucional", mas um limite para a capacidade das Organizações Internacionais moldarem a vontade dos Estados Nação.

A crise econômico-financeira iniciada em 2008 indica ser uma parte dessa dinâmica de mudanças no sistema internacional. Reflete um período mais longo do ciclo recessivo de Kondratieff que assume caráter de crise terminal, segundo Wallerstein. Para os propósitos do nosso artigo, é fundamental lembrar que há uma série de indícios de que estejamos passando por uma transição dessa hegemonia estadunidense, com reflexos muito parecidos com os momentos de crise da Liga das Nações. Principalmente, podemos apontar a baixa legitimidade das Organizações Internacionais, a crise econômica, uma dificuldade de manutenção do padrão de hegemonia por parte dos EUA e um sistema com características de multipolaridade.

No entanto, é preciso registrar que o regionalismo está cada vez mais presente neste novo cenário, com implicações para as Organizações Internacionais regionais, bem como as específicas de integração regional. A integração europeia procurou fortalecer-se desde o Tratado de Maastricht ou da Tratado da União Europeia, em 1992, e depois com a entrada de uma moeda única, o euro, com um alargamento para as antigas nações do leste europeu, bem como com o aprofundamento de suas instituições, implicando cada vez mais um desafio de interpretação e, quiçá, um exemplo a ser seguido em termos de Governança Global. Outros esquemas regionais na Ásia e na América do Sul nos remetem a pensar que estamos diante de um sistema Multipolar em Blocos, com certo nível de institucionalização, e que passa cada vez mais a ter maior importância em relação às estruturas organizacionais de caráter universal.

É importante salientar uma diferenciação em relação ao que se pode observar quanto às organizações de caráter mais técnico, como as agências especializadas da ONU, em relação ao foco maior deste artigo, as OIs de caráter político, militar e econômico. Apesar de podermos e devermos tratar todos os assuntos para os quais elas foram criadas num viés político, é inegável a contribuição delas para a normatização mundial em diversas áreas. Cabe lembrar, entre outras, as regras e procedimentos comuns definidos dentro da saúde, das telecomunicações, da aviação civil, das correspondências, da meteorologia, da cultura, da educação, do trabalho, etc..

Por último vale a lembrança acerca do esforço empreendido pela ONU com a definição dos Objetivos de Desenvolvimento do Milênio - ODM, delimitados pelos Estados-membros para a diminuição ou até erradicação dos principais problemas que assolam o mundo, principalmente os mais pobres. Não é solução para os males que um modo de produção não dá conta, mas mostra a capacidade, desde a perspectiva de uma Organização Internacional, de se colocar na agenda uma temática fundamental para milhões de seres 
humanos independentemente da nacionalidade.

\section{CONSIDERAÇÕES FINAIS}

Procuramos neste trabalho situar a trajetória das Organizações Internacionais como componente da história das relações internacionais. Assim, nos últimos 200 anos é possível vislumbrar o fenômeno das OIs como parte importante do sistema internacional, apesar de termos claro os limites que um recorte longitudinal amplo possui. Neste sentido, buscamos explicitar as marcas que compõem essa relação ao apontar os principais elementos que o cercam, concentrando nossas atenções para as dimensões da segurança e da economia.

As discussões elencadas neste trabalho não pretendem esgotar debates levantados nas questões iniciais, mas acreditamos contribuir para seu desenvolvimento posterior. $\mathrm{O}$ fenômeno das OIs parece que se tornou estrutura permanente no ambiente internacional. A característica de dependência de trajetória, verificada e teorizada para as instituições como um todo, serve muito para explicar essa situação.

Nesta linha, é possível vislumbrar uma nítida dificuldade em se perceber as OIs moldando comportamento dos Estados, o que resultaria em compreensão semelhante para a noção de "Governança Global", tanto a atual como a pretérita. Principalmente em momentos de crise econômica e de hegemonia, e os ciclos de Kondratieff nos auxiliam a percebê-los mais claramente, o que verificamos é a baixa legitimidade das Organizações Internacionais no cumprimento de seus objetivos, portanto, no alcance de efetividade. Prevalecem, invariavelmente, as principais metas e interesses estratégicos dos mais significativos Estados nacionais.

É possível indicar que, em assuntos de alta política, principalmente segurança e economia, a estratégia dos Estados nacionais não poupa ou não se preocupa com a deterioração da capacidade e legitimidade das OIs. Quando isso é verificado para os casos da Liga das Nações e o Conselho de Segurança da ONU, de forma comparada, percebemos muitos padrões recorrentes. A cada passo dos EUA em tentar manter suas prerrogativas hegemônicas, através de ações militares unilaterais e da não reciprocidade econômica, mais a ONU deixa de representar uma possibilidade de espaço de resolução de conflitos internacionais, de segurança e paz mundial. Da ONU em direção a outras Organizações Internacionais, como a própria $\mathrm{OMC}$, tem-se um efeito demonstração e contagiante de deslegitimação e diminuição de importância no Sistema Internacional, a exemplo do período da Liga das Nações.

Outros atores e agrupamentos de países estão se fortalecendo e tornando ainda mais difícil as potencialidades dos EUA regerem de forma efetiva uma hegemonia. Exemplos disso é a capacidade da União Europeia enquanto bloco, e de grandes países e potências regionais como China, Japão, 
Índia e Brasil. Neste sentido, propomos a perspectiva de que o Sistema Internacional está se reordenando numa multipolaridade em blocos, onde se percebe a diminuição da hegemonia dos EUA e a pulverização de poder no sistema, com ênfase para a consolidação de poderes regionalmente relevantes, com amplos reflexos na ordem internacional. Esta característica do sistema internacional possui suas peculiaridades pelo componente de blocos, mas muito se assemelha à multipolaridade do período da existência da Liga das Nações.

Diferentemente daquele movimento, é possível vislumbrar papel de grande valor em Organizações Internacionais, mas principalmente de caráter regional e em processos de integração. A situação deste início de novo milênio pode ser associada como de retornos decrescentes das vantagens iniciais dos países membros permanentes do CSNU. Rupturas significativas com na ordem internacional podem se constituir em conjunturas críticas, da forma como é concebida na literatura da escola do institucionalismo histórico, culminando em possibilidades de mudanças na organização.

As dimensões diretamente importantes para os Estados nacionais e suas estratégias são acompanhadas de dificuldades para a legitimidade e efetividade de Organizações Internacionais. Porém, em assuntos de baixa política, técnicos ou especializados, podemos notar elementos de "Governança Pública", na forma como vem sendo discutido o conceito desde a década de noventa. Ao menos nesses temas menos sensíveis aos Estados, a situação nos parece suficientemente desenvolvida neste trabalho a ponto de motivar o leitor a investir em pesquisas aprofundadas sobre o papel das OIs no sistema internacional.

\section{NOTAS}

${ }^{1} \mathrm{O}$ conceito de Organizações Internacionais aqui delimitado está muito próximo do utilizado por DIEZ DE VELASCO, Manuel. Las Organizaciones Internacionales. 11. ed. Madrid: Tecnos, 1999 (1 ${ }^{a}$ ed. 1977) e por SEITENFUS, Ricardo. Manual das Organizações Internacionais. 2. ed. Porto Alegre: Ed. dos Advogados, 2000. Um conceito mais amplo, que envolve outras instituições internacionais está em HERZ, Mônica; HOFFMAN, Andréa Ribeiro. Organizações Internacionais: história e práticas. Rio de Janeiro: Elsevier, 2004.

2 Trata-se de HURRELL, Andrew. Sociedade Internacional e Governança Global. In: Revista Lua Nova, São Paulo, CEDEC, n. 46, p. 55-75, 1999. Uma outra referência aqui utilizada sobre Governança Global poderá ser encontrada em ROSENAU, James N.; CZEMPIEL, Erns-Otto. Governança sem governo: ordem e transformação na política mundial. Brasília: Ed. Unb; São Paulo: Imprensa Oficial do Estado, 2000.

3 A linha aqui adotada para essas categorias parte tanto da Ciência Política quanto da economia, a destacar: HALL, Peter; TAYLOR, Rosemary C. R. As três versões do Neoinstitucionalismo. Revista Lua Nova, São Paulo, CEDEC, Political Science and the three New Institutionalisms. Publicado originalmente em Political Studies, dec. 1996. Uma 
primeira versão foi apresentada pelos autores em 1994, no congresso da American Political Science Association e numa reunião no mesmo ano na Universidade de Maryland, sobre "What is Institutionalismo Now?"; TSEBELIS, George. Jogos ocultos: escolha racional no campo da política comparada. São Paulo: Edusp, 1998; KEHOANE, R. O.; MARTIN, L. Delegation to International Organizations, comunicação apresentada à reunião de 1994, citada;MARTIN, L. L. Interests, Power and Multilateralism. International Organization, 46, 4, pp. 765-792, 1992; THELEN, Kathlen. Historical institutionalism in comparative politics. Annual Review of Political Science, 2, 1999; ARTHUR, W. Brian. Competing technologies, increasing returns, and lock-in by historical events. Economy Journal, J. 99:116.31, 1989; ARTHUR, W. Brian. Increasing Returns and Path Dependence in the Economy. Ann Arbor: University of Michigan Press, 1994; David, P. A. Clio and the economics of QWERTY. American Economy Review, 75(2):332.37, 1986; PIERSON, Paul. Increasing Returns, Path Dependence, and the Study of Politics. American Political Science Review, June, 2000; NORTH, Douglass C. Institutions, Institutional Change and Economic Performance. Cambridge: Cambridge University Press, 1990. Essa análise enfatiza as dificuldades dos países em vias de desenvolvimento de romperem as barreiras institucionais (path dependency) para crescerem economicamente. Segundo esse autor, a Path Dependency "incentiva" uma adaptação dos indivíduos às situações existentes.

${ }^{4}$ Baseado principalmente nos estudos desenvolvidos por WALLERSTEIN, Immanuel. The Capitalist World-Economy, Cambridge: Cambridge University Press, 1979; WALLERSTEIN, Immanuel. O Declínio do Poder Americano. Rio de Janeiro: Contraponto, 2004. Nikolai Kondratieff foi um economista russo que em 1924 apontou estatisticamente a ocorrência de ciclos de aproximadamente cinquenta (50) anos de duração na economia capitalista. Esses ciclos são compostos por duas fases, uma ascendente (A) de maior crescimento e pujança econômica, e outra descendente (B), caracterizada por estagnação e crise. Cada ciclo representa um grande período de aparecimento e difusão de inovações na economia capitalista, com suas respectivas implicações para a taxa de lucro.

${ }^{5} \mathrm{O}$ critério adotado para a criação das OIs neste trabalho é o da assinatura do Tratado ou Acordo de sua criação, não sua entrada em vigor, o que, em geral, ocorre de um a dois anos depois.

${ }^{6}$ A categorização das OIs em "gerações", como utilizado no nosso trabalho, é originária das atividades acadêmicas da Professora Maria Odete de Oliveira, notadamente na disciplina de Organizações Internacionais do Programa de Pós-Graduação em Direito da UFSC e em suas diversas publicações. As Agências Especializadas da ONU são Organizações Internacionais autônomas, com fins específicos, que assinam acordo com a ONU para cooperarem em direção aos Propósitos contidos na Carta das Nações Unidas. Desta forma, fazem parte do chamado sistema das Nações Unidas. Hoje existem 15 (quinze) delas, mais 3 (três) relacionadas (AIEA, OPAQ e OMC).

${ }^{7}$ CARR, Edward Hallett. Vinte anos de Crise: 1919 - 1939. Brasília: Ed. UnB, 1981.

${ }^{8}$ Acerca da Cruz Vermelho como OIs sui generis, conforme apontado neste trabalho, ver: KRIEGER, César Amorim. Direito Internacional Humanitário: o precedente do Comitê Internacional da Cruz Vermelha e o Tribunal Penal Internacional. Curitiba: Juruá, 2004.

${ }^{9}$ O termo "vetar" não está escrito na Carta da ONU, e significa o voto contrário de pelo menos um dos membros permanentes do CSNU. Durante a Guerra Fria foram 179 vetos a projetos de Resoluções que foram à votação, enquanto que do pós-Guerra Fria até 2012 foram apenas 27. Apesar do uso recorrente do termo "congelamento", há um debate sobre em que circunstâncias ele teria ocorrido e qual a significância para a ordem internacional da época. Um bom estudo com os dados citados e muitos outros sobre o assunto está em: 
HORTA, Luiz Fernando Castelo Branco Rebello. Guerra Fria e bipolaridade no Conselho de Segurança das Nações Unidas: entre conflitos e consensos. 2013. 124 f., il. Dissertação (Mestrado em Relações Internacionais) — Universidade de Brasília, Brasília, 2013.

${ }^{10}$ De fato, segundo estudos de Kilsztajn (1989), o padrão ouro-dólar existiu efetivamente apenas entre 1958 e 1960. KILSZTAJAN, Samuel. O Acordo de Bretton Woods e a evidência histórica: o sistema financeiro internacional no pós-guerra. São Paulo, Revista de Economia Política, vol. 9, no. 4, outubro-dezembro/1989, pp. 88-100.

11 Textos fundacionais e desenvolvimentos posteriores desse debate em: KEOHANE, Robert; NYE, Joseph S. Transgovernmental Relations and International Organization. World Politics, Vol. 27, No. 1, pp. 39-62, Oct., 1974; KEOHANE, Robert; NYE, Joseph S. Power and Interdependence: Word Power in Transition. Boston: Little Brown, 1977; KEOHANE, Robert O. International institutions: can interdependency work? Foreign Policy, no 10, 8296, Spr' 98.

${ }^{12}$ Para aprofundamento dos estudos acerca dos Processos de Integração regional e sua institucionalidade, ver: SILVA, Karine de Souza; COSTA, Rogério Santos da. Organizações Internacionais de integração regional: União Europeia, Mercosul e Unasul. Florianópolis: Funjab/Ufsc, 2013; SILVA, Karine de Souza. Direito da Comunidade Européia: fontes, princípios e procedimentos. Ijuí: Ed. Unijuí, 2005; OLIVEIRA, Odete Maria de. Velhos e novos regionalismos: uma explosão de acordos regionais e bilaterais no mundo. Ijuí: Editora Unijuí, 2009.

${ }^{13}$ Para melhor entendimento sobre os aspectos da Guerra do Golfo e suas implicações conforme se indica neste trabalho, ver principalmente: PATRIOTA, Antonio de Aguiar. $O$ Conselho de Segurança após a Guerra do Golfo: a articulação de um novo paradigma de segurança coletiva. Brasília: Instituto Rio Branco, Fundação Alexandre de Gusmão; Centro de Estudos Estratégicos, 1998; LAMAZIÈRE, Georges. Ordem, Hegemonia e Transgressão: a Resolução 687 (1991) do Conselho de Segurança das Nações Unidas, a Comissão Especial das Nações Unidas e o regime internacional de não proliferação de armas de destruição em massa. Brasília: Instituto Rio Branco, Fundação Alexandre de Gusmão; Centro de Estudos Estratégicos, 1998.

${ }^{14}$ Para a temática da OTAN, sua trajetória desde a criação, as transformações no pós-Guerra Fria, a sua relação com a Guerra do Kosovo e o conceito de "intervenções humanitárias" adotado a partir daquele momento, por exemplo, no caso da Líbia, ver: RAYA, Maria Augustias Caracuel. Los câmbios de la OTAN trás el fin de la guerra fría. Madrid: Tecnos, 1997; COSTA, Rogério Santos da. Organização do Tratado do Atlântico Norte (OTAN): histórico, características, objetivos, funcionamento e influência na segurança coletiva. In: Relações Internacionais no mundo atual, Faculdades Integradas Curitiba, ano VI, n. 6, p. 128-150, 2006; FRANÇA, Paulo Roberto Caminha de. A guerra de Kosovo, a OTAN e o conceito de "Intervenção Humanitária". Porto Alegre: Editora da UFRGS, 2004.

\section{Artigo recebido em janeiro de 2015. Aceito em março de 2015.}

